\title{
DIGITAL DOCUMENTATION OF FRANK LLOYD WRIGHT'S MASTERPIECE, FALLINGWATER
}

\author{
Pamela Jerome $^{\text {a }}$, Douglas Emilio ${ }^{\text {a }}$ \\ ${ }^{a}$ Architectural Preservation Studio, DPC, 740 Broadway, New York, NY 10003 USA (jeromep, \\ emiliod)@preservationstudio.com
}

Commission II, WG VI/4

KEY WORDS: Digital documentation, Fallingwater, Frank Lloyd Wright

\begin{abstract}
:
Since 1988, the professional staff of Architectural Preservation Studio (APS) has been involved with the conservation of Frank Lloyd Wright's Fallingwater in Mill Run, PA. Designed and erected from 1935 to 1939 as a weekend home for the Kauffman family, the complex consists of the main house and guest house.

After five years of reports and prototype repairs, we produced a two-volume master plan. Using original Frank Lloyd Wright drawings from Avery Library as background drawings, we measured every surface and reproduced the drawings in CAD, also developing elevations of every room. Stone-by-stone drawings of every flagstone floor and terrace scheduled to be lifted were also created using overlapping film photography that was assembled into a photo mosaic. By 2005, we designed, administered and completed a four-phase exterior restoration, with the paint-stripping and repainting of interior rooms being performed during the brief winter period when the building is closed to the public on an ongoing basis.
\end{abstract}

In 2016, we were invited back to the site to review conditions and advise on routine maintenance. At that time we proposed to re-document the buildings, this time using laser-scanning. Laser-scanning of the exterior was performed in May of 2016, and of the interior in March 2017, each over the course of four days. This paper will make a comparison between manual and digital techniques in terms of Fallingwater's documentation.

\section{INTRODUCTION}

Falllingwater, considered one of Frank Lloyd Wright's masterpieces, was designed and erected from 1935 to 1939 in two phases as the weekend home of the Kaufmann family (Hoffman, 1978, 1993). Edgar Kaufman, Sr. owned a department store in Pittsburgh, PA. His son, Edgar jr. [sic] was briefly apprenticed with Frank Lloyd Wright in 1934, and introduced his father to him (Kaufmann jr., 1986). Even though Frank Lloyd Wright designed over a dozen projects for Kaufmann, Sr., only three were executed including Fallingwater's main house, guesthouse and Kaufmann, Sr.'s offices in his Pittsburgh department store (Cleary, 1999).

Fallingwater is located approximately 60 miles southeast. Perched over a waterfall on the stream Bear Run in the Laurel Highlands of western Pennsylvania, the site was a favorite swimming spot of the Kauffman family. Deeded to the Western Pennsylvania Conservancy (WPC) in 1963 with 7,000 acres of land (Weiss et al., 2001), the complex is now a house museum that sees 180,000 visitors per year.

The house suffered from 60 chronic leaks. After five years of research, reports, materials analyses, and prototype repairs, WPC recognized that the complex was going to need a more holistic approach. The buildings had never undergone a complete restoration in the nearly 70 years of existence.

The professional staff of Architectural Preservation Studio (APS), under Wank Adams Slavin Associates
(WASA), was asked to produce an existing conditions survey as a baseline by which to make future comparisons, as well as a preservation master plan. These became Volume 1: Existing Conditions Survey and Volume 2: Evaluation and Recommendations, respectively, of the preservation master plan and were completed in 1999 (Wank Adams Slavin Associates, 1999). Following documentation, from 2000-2005, we proceeded to develop and oversaw the implementation of a four-phased program of exterior restoration. Finally, we also reviewed exterior and interior paint-stripping methods, specified interior re-painting, still ongoing, as well as tested a variety of coatings for the exterior.

\section{MANUAL DOCUMENTATION}

\subsection{Development of the Preservation Master Plan}

Original Frank Lloyd Wright drawings were available at Columbia University's Avery Architectural and Fine Arts Library. Initially, we used these as background drawings on which to markup measurements. With the assistance of two summer interns, we re-measured every surface manually using conventional tape measures and laser-distance meters. This information was then transferred into Arris CAD, the software that WASA was using at the time.

Once drafted, we then recorded all deficiencies. By 1999, we had developed a two-volume preservation master plan, which included 170 existing conditions drawings. These drawings were used to produce a graphically annotated conditions survey based on a legend developed to reflect typical conditions (Figure 1). 
The preservation master plan was funded by a grant from the J. Paul Getty Trust, and was developed by APS president, Pamela Jerome, who also served as the project manager for the restoration, and reviewed by Columbia University's Prof. Norman Weiss, who was an Associate at WASA at the time and part of the team. It crystallized the results of the investigative and prototype work that WASA implemented from 1989-1994. When we originally started working at the site, each year we were asked to review specific problematic and chronic conditions. There was no indication at that time that the buildings would eventually undergo a holistic restoration. However, as the list of conditions for us to review increased, it became apparent to WPC that a piecemeal approach to repairs was inappropriate.

The opportunity to experiment with repairs over time proved advantageous to us. Over the course of several years, we implemented a variety of interventions and were able to determine what worked and what did not in terms of our repair prototypes. In addition, probes were performed during this period, reducing the number of concealed conditions to a minimum. We documented these projects in a series of unpublished reports submitted to WPC (Wank Adams Slavin Associates, 1989, 1992, 1991, 1993, 1994). Thus, the preservation master plan reflected a consensus based on the actual experience of tested interventions in order to develop appropriate long-term results during restoration.

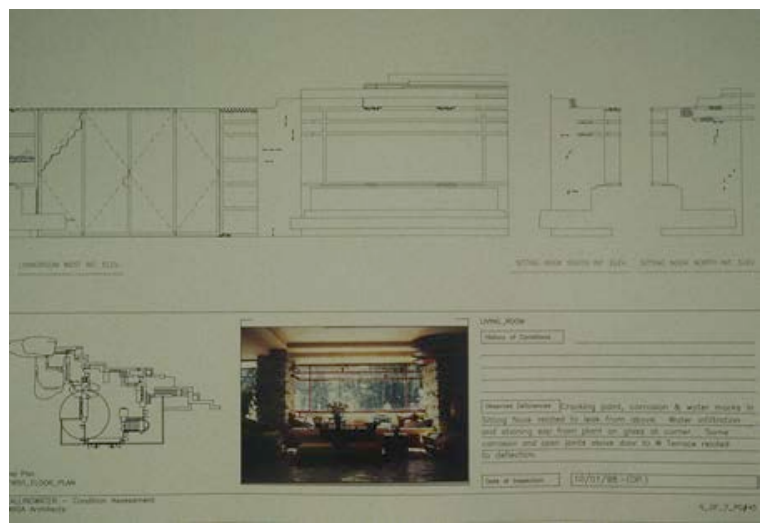

Figure 1. Page from the existing conditions survey (Wank Adams Slavin Associates, 1999)

\subsection{Development of Construction Documents and Implementation of Exterior Restoration}

With the completion and approval of the preservation master plan, we were retained to design and administer a comprehensive program of exterior restoration. The work was divided into four phases, as the buildings were to remain open for public tours throughout the construction period. Because of the chronic leaks, the restoration entailed the re-roofing of all roofs and re-waterproofing of all terraces. In addition, there was widespread failure of the stuccoed concrete surfaces. The steel-casement windows and doors were corroding, although WASA had already overseen the restoration of the hatch over the stairs to the stream during an earlier campaign. Both stuccoed concrete and steel features were restored as part of the construction project. Certain features were to be reconstructed, like the stairs to the stream, which were already a failed reconstruction; this was decided only after several of WASA's attempts to use trowel-applied patches and cast-in-place patches had also failed (Weiss et al., 2001). The disassembly and reassembly of the stone cheek walls adjacent to the walkway to the guest house beneath the stepped canopy, which had shifted due to frost, were also included as part of the project, along with the restoration of the leaking skylights.

The system of construction of Fallingwater's slabs relies on an upside-down " $T$ " configuration, wherein the slabs are the soffits or ceilings of the spaces and rooms below, and the beams are upturned within a cavity that also contains concrete joists. The terraces have flagstones as the finished surface, whereas the actual three plies of waterproofing membranes were applied to a marinegrade plywood decks resting on the joists and beams. On top of the waterproofing was placed drainage mat and a dry-pack setting bed for the flagstones. In the waterproofing industry, this is known as an inverted roofing membrane assembly (IRMA).

Robert Silman Associates, structural engineers, had monitored the creep of the cantilevers over the course of several years and had come to the conclusion that it was ongoing (Silman, 2000). The upturned cantilever beams of the living room along with those of its terraces were to be post-tensioned to halt this progressive creep, which had caused the cantilevers to deflect by as much as 7" (Figure 2). For the premiere space of the main house, the living room, this meant that the flagstone floor and builtin furniture had to be removed in order to access the tops of the cantilever beams and grout any cracks; this was done to prevent the post-tensioning from substantially lifting the living-room slab during structural reinforcement, thereby damaging the windows along the south end, which followed the sag of the cantilevers (Figure 3).

In addition to the terraces and living room, there was also the flagstone floor of the enclosed bridge to the guesthouse. Here, a trickle of water was purposely left by Frank Lloyd Wright to come through the natural bedrock that is built into the north wall. Over the years, the water from this small stream had damaged the floor slab that spans over the driveway. To eliminate this source of deterioration, this slab was also designated for waterproofing (Jerome et al., 2006).

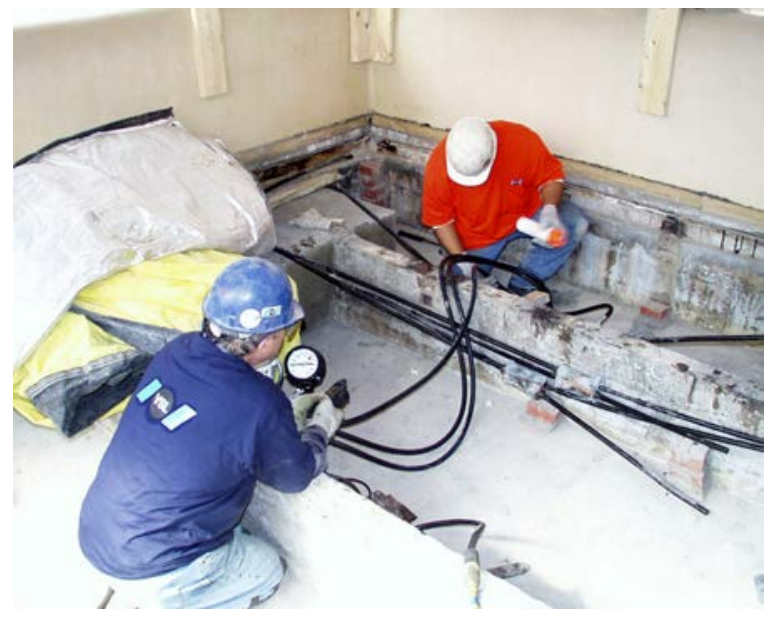


Figure 2. Post-tensioning cables being installed to structurally reinforce Fallingwater's sagging cantilevers; in this case they are being applied to concrete joists on one of the living-room terraces (courtesy of Robert Silman Associates, 2004)

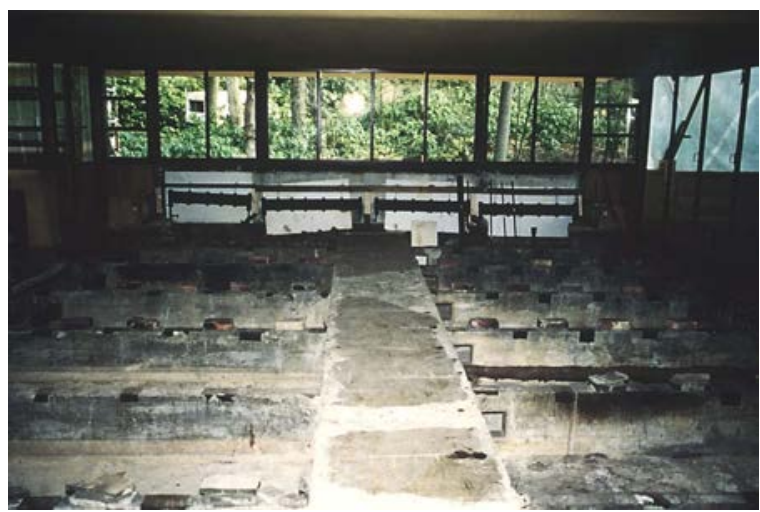

Figure 3. The gutted living room looking south at the windows (Wank Adams Slavin Associates, 2004)

Stone-by-stone documentation was performed of original flagstone surfaces for terraces and interior spaces to be lifted for waterproofing of concealed decks and/or for reinforcement of cantilever beams. Because the flagstone surfaces are uneven, the built-in furniture is scribed to the irregular interior stone walls, and the finished surface of the terraces is at the same height as that of the interior floor levels, it was critical to have an accurate way of removing, non-destructively labeling and reassembling the flagstones in their exact same locations and heights, like a giant jigsaw puzzle. This work was performed by Fallingwater's maintenance staff, because they had become adept at lifting the flagstones over the years to try and deal with the multitude of leaks originating from the terraces. The lifting was coordinated with the contractor so as not to leave any area exposed to precipitation during re-waterproofing.

For each of the floors or terraces to be lifted, a 2'-0" grid was marked on the flagstones utilizing masking tape. An SLR camera on a tripod at a fixed height was used to shoot photographs that overlapped by $50 \%$. The color photographs were developed and then assembled into a photo mosaic that was taped to a board. The irregular shapes of the flagstones were hand-traced onto a transparent overlay, which was scanned and imported into the CAD drawings to scale. The grid was included on the CAD drawings to help guide the reassembly of the flagstone surfaces. Each flagstone was given a unique letter and number on the drawings based on its location on the grid (Figure 4). We also produced stone-by-stone elevations and plans of the cheek walls to assist in their disassembly and reconstruction.

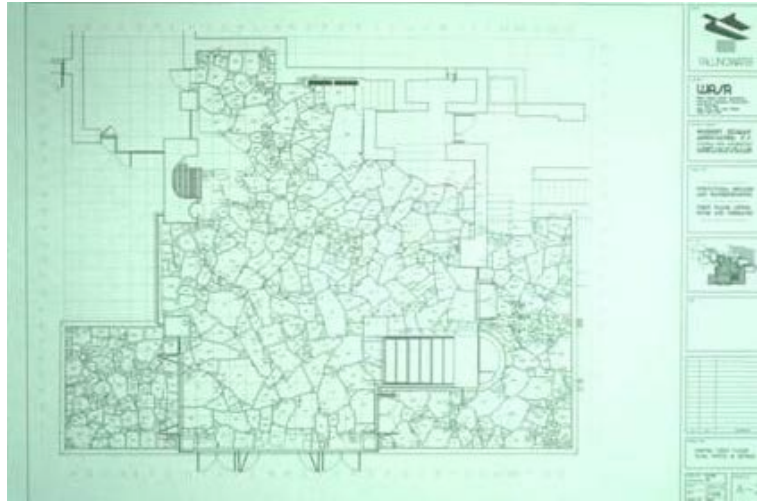

Figure 4. Documentation of the living-room flagstone floor and east and west living-room terraces (Wank Adams Slavin Associates, 2004)

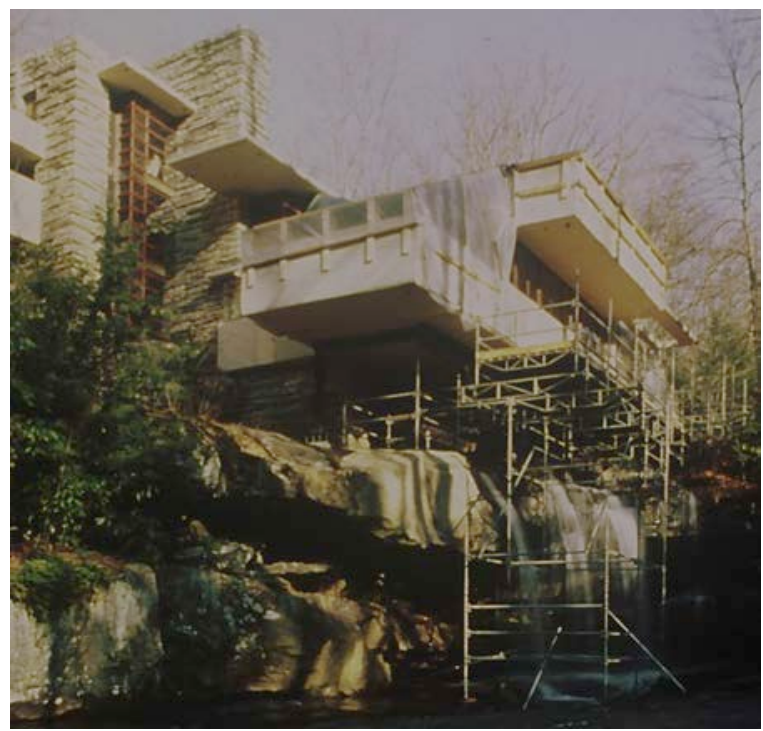

Figure 5. Fallingwater during Phase 3 of the restoration when the flagstones were lifted from the living room, its east and west terraces, and the master-bedroom terrace

above (Wank Adams Slavin Associates, 2004)

With funding from Save America's Treasures and other sources, including the state of Pennsylvania, the $\$ 13.5$ million restoration was completed by 2005 (Figure 5). During this period, the complex never closed for visitation, with the exception of the annual winter closure. Even while the living-room cantilever beams were structurally post-tensioned, the building was open for hard-hat tours.

Following paint analysis performed by Integrated Conservation Resources (ICR) in 2001, it was apparent that the interior paint had strayed from the original paint slightly roughened by the texture of the interior plaster to sanded paint (Integrated Conservation Resources, Inc., 2001). There were also multiple layers of incompatible paints causing failures. Interior restoration, though, has proceeded more slowly, with one or two rooms being mechanically paint-stripped and repainted over the brief winter breaks. 


\subsection{Digital Documentation}

In 2016, we returned to the site to assist with routine maintenance of the exterior restoration, and to resolve five leaks that have reappeared. We were also retained to perform 3D laser-scanning of the exterior and interior. Using a Faro Focus laser-scanner and AutoCAD Recap 360 Pro digital software, the site was captured. However, a high degree of coordination was required so as not to impact ongoing visitation, as the site continued to be open to the public during the laser-scanning documentation.

Except for Wednesdays, guided tours of Fallingwater occur daily at a frequency of every six minutes. Each guided tour group includes a maximum of 15 visitors. The timing and number of people are regulated by the size of the rooms, as well as the amount of time it takes for a group to view a space. The docents have the exceptional task of orchestrating this, as there can be no overlap of tour groups in rooms because with the exception of the living room, the rooms are small and intimate. The daily tours are carefully synchronized for these reasons.

Laser scanning of the exterior was executed in May 2016 while guided tours continued at a six-minute intervals. APS partner, Douglas Emilio, performed the scans and then stitched them together. Over a period of four days, all of the exterior surfaces of both buildings were captured. This included elements of the site, like the car bridge that leads to the driveway, the concrete beams over the driveway, the stepped canopy and steps below that lead to the guest house.

The interior laser scanning, however, had to wait until the building was closed to prepare for the new season of tours. A week before reopening in March of 2017, Douglas Emilio again spent four days capturing every interior surface.

Over 400 scans were completed including associated digital panoramic photographs. At the time of this paper, the scan registration is completed and APS will be working with WPC to determine how best to manage and leverage the scan data and point cloud. Potential integration includes linking archival documents, contemporary documentation including capital and routine maintenance items.

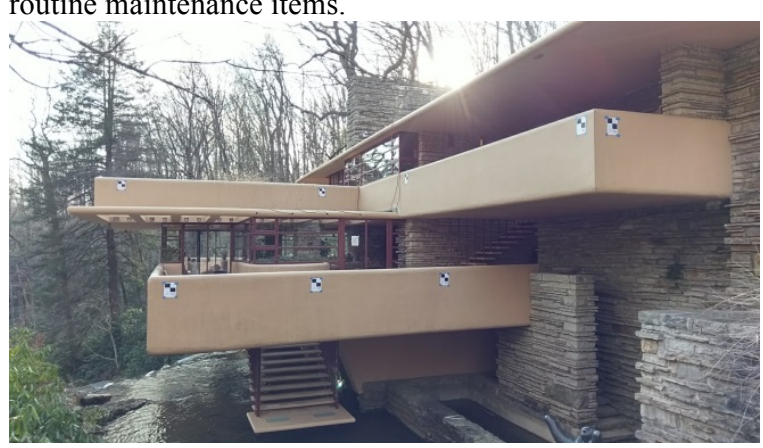

Figure 6. Scanning of the exterior of Fallingwater (Architectural Preservation Studio, 2017)

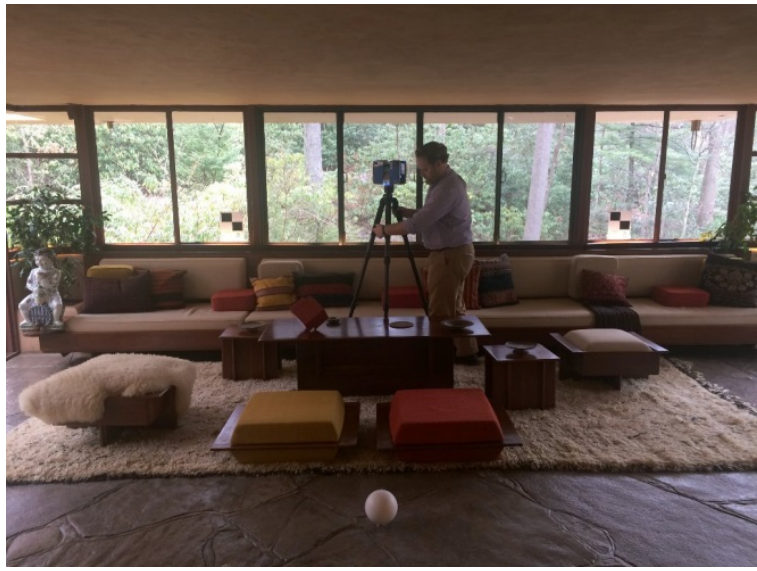

Figure 7. Scanning of the interior of Fallingwater (Western Pennsylvania Conservancy, 2017)

\section{CONCLUSION}

In the space of 15 years, the level of accuracy of conservation documentation has improved dramatically as a result of 3D-laser scanning. The resulting highdefinition $3 \mathrm{D}$ models and the information captured are far superior to our manual documentation of the past. The conversion of this information into AutoCAD makes it both accessible and usable for the client and future preservationists. The laser-scanning documentation

With a complex as unique as Fallingwater, maintenance is a never-ending process. It is critical to the long-term conservation of the site to have benchmarks of existing conditions. By having accurate documentation, the guesswork is taken out of whether or not a specific condition pre-existed. A difficult building to care for at best, Fallingwater requires the continuous commitment of the staff of WPC. At the same time, the building needs to be maintained operational for the enjoyment of the thousands of visitors who journey from around the world to see this remarkable masterpiece of Frank Lloyd Wright. Our combined efforts will hopefully ensure that this site survives in good condition for future generations to enjoy.

\section{References}

Cleary, R. 1999. Merchant Prince and Master Builder: Edgar J. Kaufmann and Frank Lloyd Wright. Heinz Architectural Center, Carnegie Museum of Art, Pittsburgh, 14.

Hoffman, D. 1978, 1993. Frank Lloyd Wright's Fallingwater: The House and Its History. Dover Publications, New York, NY, pp 8-9.

Integrated Conservation Resources, Inc. 2001. "Paint Analysis Services: Fallingwater Bear Run, Pennsylvania". Unpublished report.

Jerome, P., Weiss, N., Ephron, H., 2006. Fallingwater part 2: Materials conservation efforts at Frank Lloyd Wright's masterpiece. APT Bulletin, 37(23), pp. 3-11. 
Kaufmann jr., E. 1986. Fallingwater. A Frank Lloyd Wright Country House. , Cross River Press, New York, NY, pp. 36-39.

Silman, R. 2000. The plan to save Fallingwater. Scientific American, September, pp. 88-95.

Wank Adams Slavin Associates, 1989. "Volume 1: Fallingwater. Conservation Analysis for Concrete and Stone Masonry". Unpublished report.

Wank Admas Slavin Associates, 1991. "Volume 3: Fallingwater. Concrete Repairs and Coating Tests. Conservation Tests 1991". Unpublished report.

Wank Adams Slavin Assiciates, 1992. "Volume 2: Fallingwater. Conservation and Analysis for Concrete and Stone Masonry. Conservation Tests 1990". Unpublished report.

Wank Adams Slavin Associates, 1993. "Volume 4: Fallingwater. Concrete and Stone Masonry. Conservation Tests 1992". Unpublished report.

Wank Adams Slavin Associates, 1994. "Volume 5: Fallingwater: Crack Repairs and Coatings. Conservation Tests 1993". Unpublished report.

Wank Adams Slavin Associates, 1999. "Volume 1: Existing Conditions Survey. Volume 2: Evaluation and Recommendations". Unpublished report.

Wank Adams Slavin Associates, 2004. "Phase 3: Living Room and Master Bedroom Terraces and Roofs, Enclosed Bridge, Cheekwalls, and Foundation Dampproofing". Unpublished construction drawings.

Weiss, N., Jerome, P., Gottlieb, S., 2001. Fallingwater part 1: Materials conservation efforts at Frank Lloyd Wright's masterpiece. APT Bulletin, 32(4), pp. 44-55. 